\title{
Effects of Porosity and Pore Structure on Compression Properties of Blowing-Agent-Free Aluminum Foams Fabricated from Aluminum Alloy Die Castings
}

\author{
Yoshihiko Hangai $^{1}$, Hiroki Kato ${ }^{1, *}$, Takao Utsunomiya ${ }^{2}$, Soichiro Kitahara ${ }^{3}$, \\ Osamu Kuwazuru ${ }^{4}$ and Nobuhiro Yoshikawa ${ }^{5}$ \\ ${ }^{1}$ Graduate School of Engineering, Gunma University, Kiryuu 376-8515, Japan \\ ${ }^{2}$ Research Organization for Advanced Engineering, Shibaura Institute of Technology, Saitama 337-8570, Japan \\ ${ }^{3}$ Gundai Co., Ltd., Isesaki 372-0854, Japan \\ ${ }^{4}$ Graduate School of Engineering, University of Fukui, Fukui 910-8507, Japan \\ ${ }^{5}$ Institute of Industrial Science, The University of Tokyo, Tokyo 153-8505, Japan
}

\begin{abstract}
Aluminum foam was fabricated without the use of a blowing agent by a friction stir processing route using ADC12 aluminum alloy die castings, which contain a large number of gas pores. In this study, ADC12 foams with a porosity of 50-77\% were successfully fabricated, and the pore structures and compression properties of the obtained ADC12 foams were investigated. The ADC12 foams had smaller pores than commercially available aluminum foam. Moreover, the pore size of the ADC12 foams was almost the same regardless of the porosity. According to the results of compression tests, the plateau stress and energy absorption tend to decrease with increasing porosity. Commercially available aluminum foam exhibited higher energy absorption at a low compression stress, whereas the ADC12 foams exhibited higher energy absorption at a high compression stress. Also, the ADC12 foams with higher porosity exhibited higher energy absorption per unit mass, regardless of the compression stress. In contrast, the energy absorption per unit volume was greatest for the low-porosity ADC12 foam at a low compression stress but greatest for the high-porosity foam at a high compression stress. [doi:10.2320/matertrans.M2012125]
\end{abstract}

(Received April 2, 2012; Accepted May 22, 2012; Published July 4, 2012)

Keywords: porous metals, die casting, friction stir welding, aluminum alloy, foam, compression test, X-ray computed tomography (CT)

\section{Introduction}

Aluminum foams are expected to have a wide range of applications such as automotive components and railway equipment owing to their light weight and good energy absorption properties. ${ }^{1)}$ Aluminum foams can be fabricated using a precursor. ${ }^{1-11)}$ In this process, a foamable precursor, namely, an aluminum alloy composite that contains a uniformly distributed blowing agent powder, is fabricated first. In the heat treatment of the precursor, gases generated by the decomposition of the blowing agent expand the softened aluminum alloy to produce the aluminum foam. There are several routes for fabricating the precursor, namely, the powder metallurgical $(\mathrm{P} / \mathrm{M})$ route, ${ }^{2-5)}$ accumulative rollbonding (ARB) route, ${ }^{6,7)}$ compressive torsion processing route $^{8,9)}$ and friction stir processing (FSP) route. ${ }^{10,11)}$

Recently, an FSP route that does not require the use of a blowing agent for fabricating the precursor has been developed. ${ }^{12-14)}$ In this process, aluminum alloy highpressure die castings, which contain a large number of gas pores, ${ }^{15,16)}$ are used as starting materials for the fabrication of aluminum foams. These gas pores can be used to induce foaming as an alternative to a blowing agent, which is relatively expensive and an explosion hazard, and the porosity (density) of the resulting aluminum foam has a high correlation with the amount of gases contained in the die castings. ${ }^{13)}$ Moreover, aluminum alloy die castings can be produced with high productivity and have high recyclability. Therefore, this FSP route has the advantage of reducing the cost of $\mathrm{Al}$ foam through a process with lower environmental impact. In addition, it was shown that the pores of the $\mathrm{Al}$

*Graduate Student, Gunma University foam obtained using die castings without the use of a blowing agent are smaller and have higher sphericity than those of $\mathrm{Al}$ foam fabricated using a blowing agent. ${ }^{17,18)}$ Therefore, it is expected that the $\mathrm{Al}$ foam fabricated from aluminum alloy die castings without the use of a blowing agent will exhibit different mechanical properties from those of $\mathrm{Al}$ foam fabricated using a blowing agent. ${ }^{14)}$ Although other researchers have also demonstrated blowing-agent-free processes for fabricating $\mathrm{Al}$ foam by the $\mathrm{P} / \mathrm{M}$ route, ${ }^{19-21)}$ few studies have been conducted on these processes.

In this study, the pore structures and compression properties of aluminum foams fabricated from aluminum alloy die castings were investigated. First, several aluminum alloy die casting plates, which contain different amounts and types of gases, were prepared as starting materials for fabrication of several types of $\mathrm{Al}$ foam specimens with different porosities. Next, before conducting compression tests, X-ray computed tomography (X-ray CT) observation was carried out to characterize the pore structures of the compression test specimens. Finally, the effect of the porosity and pore structure on the mechanical properties of the fabricated $\mathrm{Al}$ foams was investigated. The results were compared with commercially available ALPORAS (Shinko Wire Co., Ltd.). ${ }^{2,23)}$

\section{Experimental Procedures}

\subsection{Fabrication of aluminum alloy die casting plates}

As the starting materials for the fabrication of the $\mathrm{Al}$ foams, $\mathrm{Al}-\mathrm{Si}-\mathrm{Cu}$ aluminum alloy $\mathrm{ADC} 12$ (equivalent to A383.0 aluminum alloy) die casting plates were used. Three different $\mathrm{ADC} 12$ die casting plates were fabricated that contained different amounts and types of gases, as shown in Table 1, by changing the die casting conditions and the 


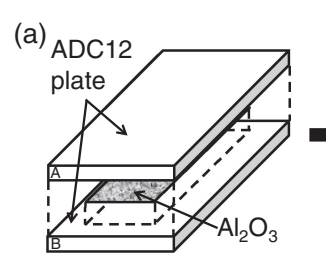

(g)

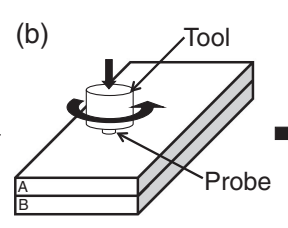

(c)

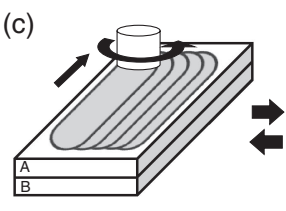

(d)

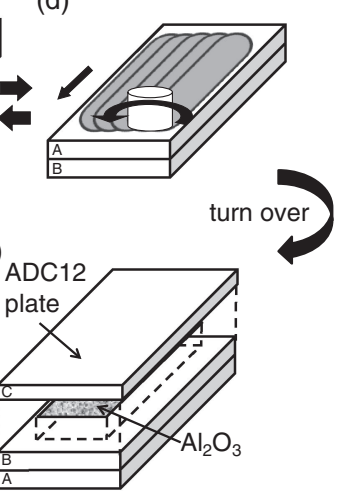

Fig. 1 Schematic illustration of the fabrication process of the precursor by FSP using aluminum alloy die casting plates.

Table 1 Types and amounts of gases in fabricated ADC12 aluminum alloy die casting plates $\left(\mathrm{cm}^{3} / 100 \mathrm{gAl}\right)$.

\begin{tabular}{crrrrrrrr}
\hline Die castings & $\mathrm{H}_{2}$ & \multicolumn{1}{c}{$\mathrm{N}_{2}$} & $\mathrm{CH}_{4}$ & $\mathrm{CO}$ & $\mathrm{CO}_{2}$ & $\mathrm{C}_{2} \mathrm{H}_{4}$ & $\mathrm{C}_{2} \mathrm{H}_{6}$ & Total \\
\hline I & 9.9 & 37.6 & 8.2 & 4.6 & 27.6 & 4.8 & 1.0 & 93.7 \\
II & 84.5 & 1.9 & 26.0 & 23.1 & 44.5 & 13.5 & 1.8 & 195.2 \\
III & 73.9 & 13.1 & 19.8 & 53.0 & 84.8 & 5.6 & 0.0 & 250.6 \\
\hline
\end{tabular}

amount of parting and lubricant agent. The amounts and types of gases were measured by gas chromatographic analysis after melting the ADC12 die casting plates. The source of $\mathrm{N}_{2}$ gas is considered to be gases existing in the cavity, the runners and the injection system. In contrast, the source of $\mathrm{H}_{2}$ and other gases such as $\mathrm{CH}_{4}$ is considered to be the reaction gases formed when the melted aluminum alloy encounters the parting and lubricant agent.

\subsection{Fabrication of ADC12 Al foams}

Figure 1 shows a schematic illustration of the fabrication process of the precursor by the FSP route. Details of the FSP procedure for fabricating precursors have been described elsewhere. ${ }^{11,14)}$ Briefly, two plates were stacked with alumina powder $\left(\alpha-\mathrm{Al}_{2} \mathrm{O}_{3}, \sim 1 \mu \mathrm{m}\right)$ distributed between them as the stabilization agent. The amount of alumina used was 5 mass $\%$ of the mass of the aluminum alloy with dimensions of the area over which alumina was distributed and the length of the tool probe. The gases, which are segregated in the die castings, and alumina powder are expected to be uniformly distributed by conducting FSP. ${ }^{24,25)}$ FSP was carried out using a 1D-FSW machine (Hitachi Setsubi Engineering Co., Ltd.). The multipass FSP technique ${ }^{26,27)}$ was applied to obtain a larger amount of precursor and to mix the segregated gases and alumina powder thoroughly. To obtain a thicker precursor, four die casting plates were used and layered for die casting I, and three die casting plates were used and layered for die castings II and III. The differences of the size of the precursors were due to differences in the expansion efficiency, which depends on the total amount of gases contained in the die casting plates, to obtain the compression specimen.

The precursor sample was placed in the die and then heated in a preheated electric furnace. The holding temperature (equal to the preheating temperature) and the holding time during the heating process were fixed at $948 \mathrm{~K}$ and 12 $13 \mathrm{~min}$, respectively, with reference to a previous study. ${ }^{13,14)}$
We respectively refer to the ADC12 foams fabricated from die castings I, II and III as ADC12 foams I, II and III, hereinafter.

The ADC12 foams were cut by electro-discharge machining to fabricate cubic compression specimens. The specimen of ADC12 foam I had a side of $15 \mathrm{~mm}$, whereas those of ADC12 foams II and III had a side of $20 \mathrm{~mm}$. The different sizes of the specimens was due to differences in the expansion efficiency, which depends on the total amount of gases contained in the die casting plates. In addition, cubic compression specimens with a side of $25 \mathrm{~mm}$ were fabricated from the as-received ALPORAS. The size of each specimen was selected so that there were at least seven pores on each face of the specimen to avoid the edge effect.

\subsection{Evaluation of pore structures}

Before the compression tests were conducted, the pore structures in the ADC12 foams and ALPORAS compression test specimens were observed nondestructively by X-ray CT using an SMX-225CT microfocus X-ray CT system (Shimadzu Corporation) at room temperature as in previous studies. ${ }^{28)}$ The X-ray tube voltage and current were $80 \mathrm{kV}$ and $30 \mu \mathrm{A}$, respectively. The areas $A$ and average diameters $d_{\mathrm{m}}$ of the pores were evaluated from two-dimensional crosssectional X-ray CT images using WinROOF image processing software (Mitani Corporation). An appropriate threshold was set to distinguish the aluminum and the pores, and binarized X-ray CT images were established for the evaluation. Pores with areas of less than $0.4 \mathrm{~mm}^{2}$ were excluded owing to the resolution of the X-ray CT images. ${ }^{29)}$

The porosity $p(\%)$ of the compression test specimens was calculated as

$$
p=\left(\rho_{\text {precursor }}-\rho_{\text {specimen }}\right) / \rho_{\text {precursor }} \times 100,
$$

where $\rho_{\text {precursor }}$ is the density of the precursor before heating, which was evaluated by Archimedes' principle, and $\rho_{\text {specimen }}$ is the density of the compression test specimen, which was evaluated from the weight and dimensions of the specimen.

\subsection{Compression test procedure}

Compression tests were carried out at room temperature in ambient air using an Autograph AG-100kNG universal testing machine (Shimadzu Corporation). The compression strain rate was set as $4.2 \times 10^{-3} \mathrm{~s}^{-1}$. During the tests, the deformation of the specimen was observed by video recording. Three to five compression tests was conducted for each ADC12 foam. 


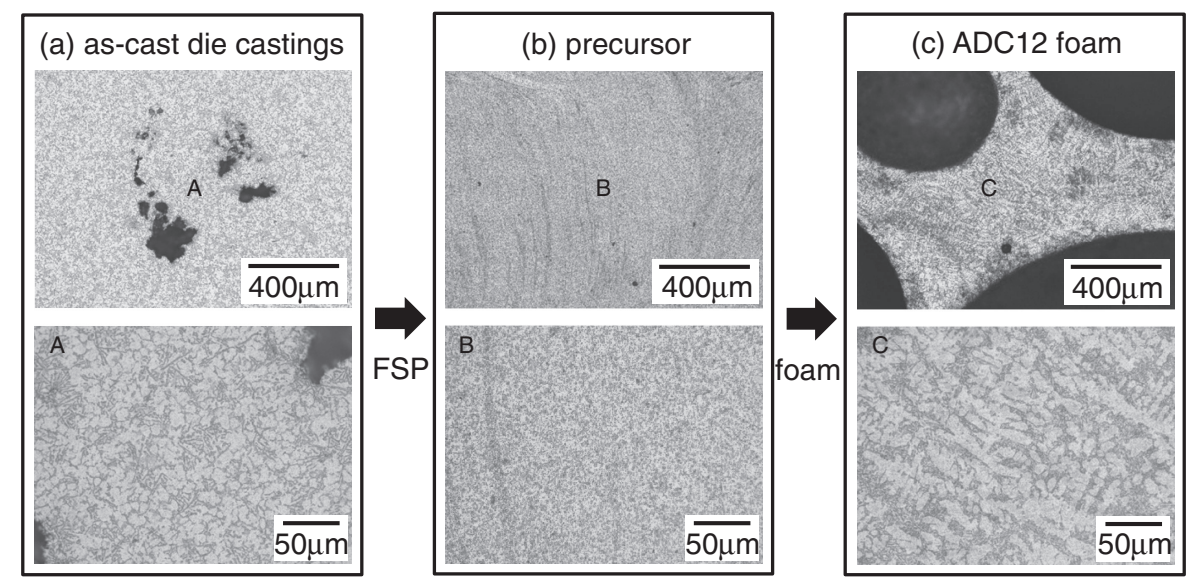

Fig. 2 Sample microstructures of (a) as-cast die castings before FSP, (b) precursor after FSP and (c) ADC12 foam fabricated in this study.

\section{Results and Discussion}

\subsection{Microstructure and pore structure of ADC12 foams}

Figure 2 shows the sample microstructures of ADC12 die casting plates before FSP (the starting material, i.e., as-cast die castings), after FSP (precursor) and the ADC12 foam. Before FSP, as shown in Fig. 2(a), many gas pores existed in the specimen, and the gas pores and microstructures were relatively segregated. After FSP, as shown in Fig. 2(b), fewer gas pores were observed and the microstructure became fine and uniformly dispersed. It is considered that the gases were also distributed uniformly after conducting FSP. These gases expanded upon the heat treatment of the precursor to generate pores. It is expected that the generated pores have a uniform morphology and distribution by distributing gases conducting FSP. In the microstructure of the ADC12 foam shown in Fig. 2(c), dendrites of aluminum can be clearly observed, which indicated that directional solidification occurred in the foaming specimen in contrast to the as-cast specimen. The values of dendrite arm spacing II (DAS II) ${ }^{30)}$ for the as-cast specimen and the ADC12 foam were 10.5 and $8.62 \mu \mathrm{m}$, respectively, which indicated that the rate of solidification after foaming was slightly higher than that during the die casting process. Moreover, an $\mathrm{Al}-\mathrm{Si}$ eutectic microstructure, which is considered to indicate brittle behavior, can be observed.

Figure 3 shows the compression test specimens of ADC12 foam II $(p=70.8 \%)$ and ALPORAS $(p=88.9 \%)$. Figure 4 shows two-dimensional cross-sectional X-ray CT images of the compression test specimens of ADC12 foams I $(p=49.0 \%)$, II $(p=70.8 \%)$ and III $(p=76.5 \%)$ and ALPORAS $(p=88.9 \%)$. White regions indicate the aluminum alloy and gray regions indicate pores. It can be seen that the ADC12 foams had smaller pores with higher sphericity than those of ALPORAS. Also, the pore size of the ADC12 foams was almost the same regardless of the porosity.

Figure 5 shows the relationship between the total amount of gases contained in the as-cast die casting plates and the porosity of the obtained ADC12 foams. An approximately linear relationship is shown in the figure and the correlation coefficient was 0.9864 . Thus, the total amount of gases had a strong correlation with the porosity of the ADC12 foams, which is consistent with the results of previous studies. ${ }^{13)}$
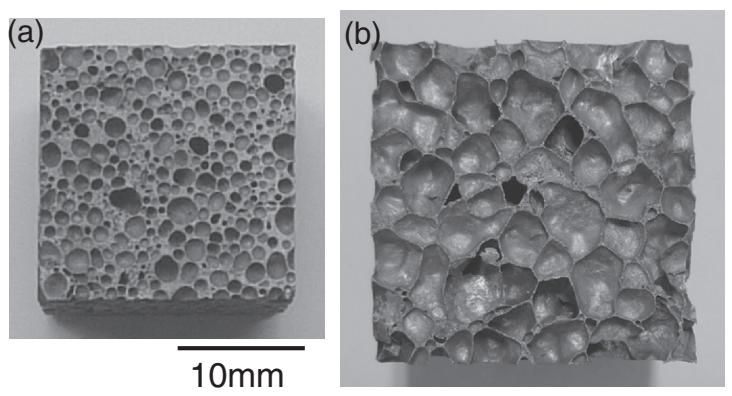

Fig. 3 Compression test specimens of (a) ADC12 foam II $(p=70.8 \%)$ and (b) ALPORAS $(p=88.9 \%)$.

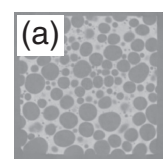

$5 \overline{\mathrm{mm}}$
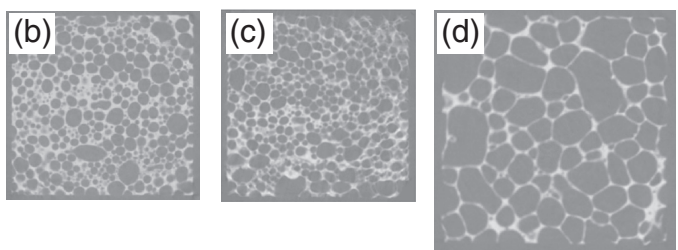

Fig. 4 Two-dimensional cross-sectional X-ray CT images of the compression test specimens: (a) ADC12 foam I ( $p=49.0 \%$ ), (b) ADC12 foam II $(p=70.8 \%)$, (c) ADC12 foam III $(p=76.5 \%)$ and (d) ALPORAS $(p=88.9 \%)$.

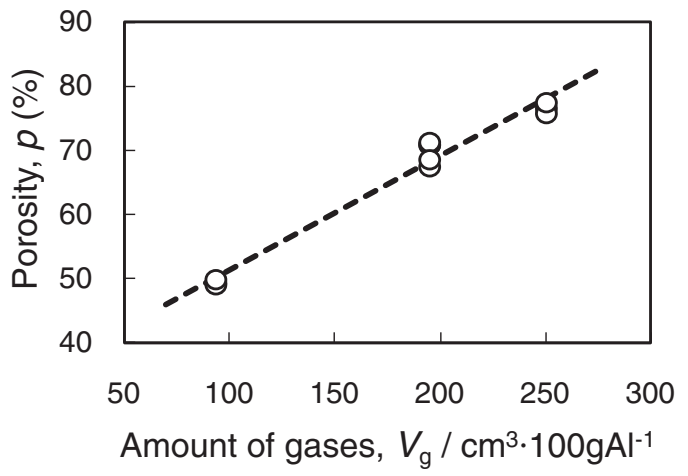

Fig. 5 Relationship between the total amount of gases and the porosity of ADC12 foams. An approximately linear relationship is indicated.

Figure 6 shows the relative frequency (the ratio of the number) of the pore area $A$ for ADC12 foams I ( $p=49.0 \%)$, II $(p=70.8 \%)$ and III $(p=76.5 \%)$ and ALPORAS $(p=$ $88.9 \%)$, for which the total numbers of pores evaluated were 


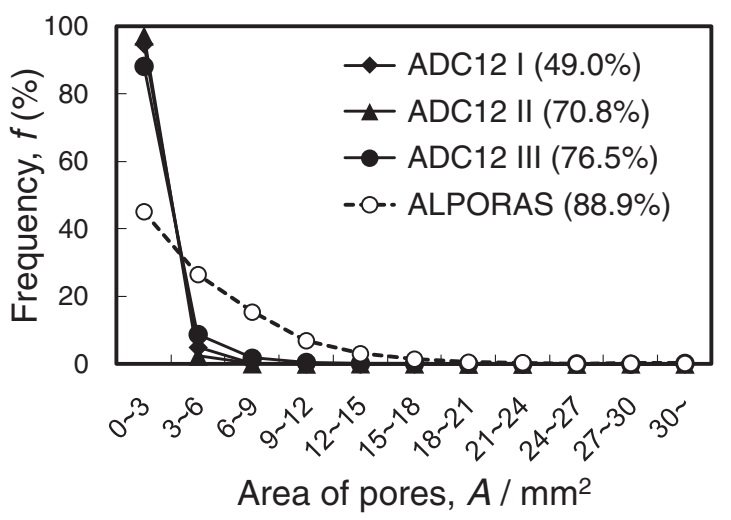

Fig. 6 Relative frequency of pore area $A$ for $\mathrm{ADC} 12$ foams and ALPORAS.

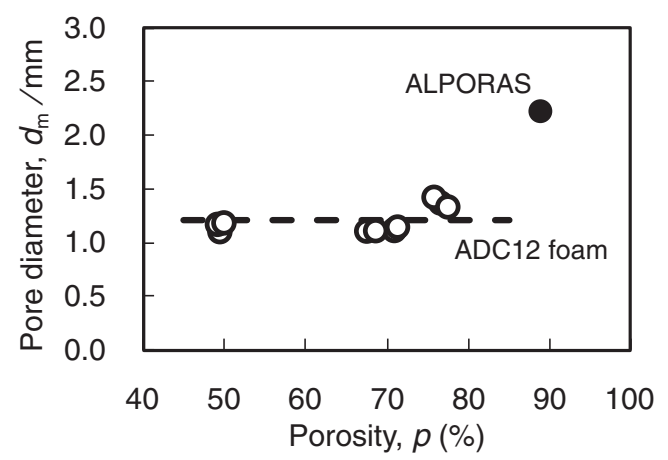

Fig. 7 Relationship between porosity of the foams and average pore diameter $d_{\mathrm{m}}$.

972, 2617, 3547 and 1430, respectively. For the ADC12 foams, more than $80 \%$ of the pores had an area of less than $3 \mathrm{~mm}^{2}$, and the frequency of pores rapidly decreased with increasing pore area. This tendency was observed for all the ADC12 foams regardless of the porosity. In contrast, for ALPORAS, approximately $40 \%$ of the pores had an area of less than $3 \mathrm{~mm}^{2}$, and the frequency of pores gradually decreased with increasing pore area. Therefore, the pores in the ADC12 foams were smaller and had a narrower distribution than those in ALPORAS.

Figure 7 shows the relationship between the porosity of the foams and the average pore diameter $d_{\mathrm{m}}$. It can be seen that the average pore diameters for the ADC12 foams were almost the same regardless of the porosity and were smaller than that for ALPORAS. Therefore, Figs. 6 and 7 indicate that the pore size of the ADC12 foams was not affected by the amount of gases contained in the as-cast die casting plates (starting materials) or the porosity of the obtained ADC12 foams.

\subsection{Mechanical properties of ADC12 foams}

Figure 8 shows typical stress-strain curves obtained under compression for the ADC12 foams of different porosities and ALPORAS. All stress-strain curves consist of an elastic region, a plateau region and a densification region. The compression stress of all the ADC12 foams decreased after attaining the first peak stress, and thereafter slightly increased with indicating up and down of compression stress. This tendency was consistent with the stress-strain behavior of ADC12 foam fabricated using a blowing agent, ${ }^{31)}$ which is

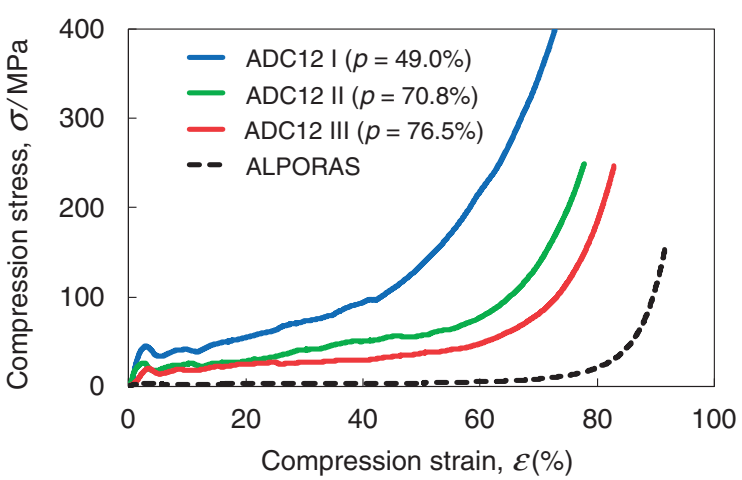

Fig. 8 Typical stress-strain curves obtained under compression for the ADC12 foams and ALPORAS.

attributed to the eutectic nature of ADC12 aluminum alloy. The ADC12 foams had a higher plateau stress but a narrower plateau region than ALPORAS. For the ADC12 foams, with decreasing porosity, the plateau stress increased and the plateau region became narrower.

Figure 9 shows sequential deformation images of ADC12 foam II $(p=70.8 \%)$ and ALPORAS $(p=88.9 \%)$ under compression loading. The ADC12 foam exhibited localized brittle fracture and fragments of the collapsed foam can be seen. This tendency was observed for all ADC12 foams regardless of the porosity. In contrast, ALPORAS exhibited ductile fracture. This failure mode is consistent with that reported in the literature, ${ }^{32-34)}$ in which ALPORAS (pure Al) exhibited a ductile fracture mode; in contrast, $\mathrm{Al}-\mathrm{Si}-\mathrm{Mg}$ and $\mathrm{Al}-\mathrm{Zn}-\mathrm{Mg}$ alloy foams exhibited a brittle fracture mode. This brittle fracture of the ADC12 foams is due to the microstructure of the cell walls being primarily composed of eutectic Al-Si, as shown in Fig. 2(c), which is considered to have low ductility.

Figures 10(a) and 10(b) respectively show the relationships between the porosity and the plateau stress $\sigma_{\mathrm{pl}}$ (the average stress for a strain of $20-30 \%{ }^{35)}$ ) and energy absorption per unit volume $E_{\mathrm{V}}{ }^{50}$ (the area under the stressstrain curve up to $50 \%$ strain divided by the initial volume of the foam ${ }^{35)}$ ) for the ADC12 foams. The figure shows that the plateau stress and energy absorption tend to decrease with increasing porosity, and they indicated the strong relationship. The plateau stress and energy absorption exhibited almost the same tendency with increasing porosity. Therefore, it is considered that the plateau stress strongly affects the energy absorption regardless of the porosity of the ADC12 foams.

Figure 11(a) shows the relationship between the compression stress $\sigma$ and energy absorption per unit volume $E_{\mathrm{V}}$ (the area under the stress-strain curve up to a specific stress divided by the initial volume of the foam) for the ADC12 foams with different porosities and ALPORAS. ALPORAS had a higher $E_{\mathrm{V}}$ in the first stage of compression up to $\sigma \approx 25 \mathrm{MPa}$. This is because ALPORAS has a low plateau stress, and therefore it deformed with a large compression strain at low compression stress. In contrast, the ADC12 foams have a high plateau stress and therefore remained in the elastic region at low compression stress. As the compression behavior of the ADC12 foams departed from the linear elastic region, $E_{\mathrm{V}}$ increased rapidly, in contrast to ALPORAS, and $E_{\mathrm{V}}$ for the ADC12 foams became higher 
(a)
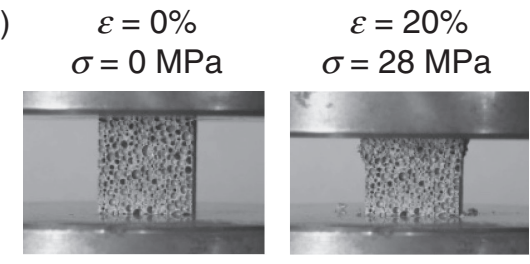

$\varepsilon=40 \%$

$\varepsilon=60 \%$

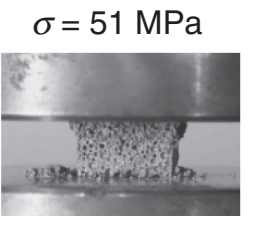

$$
\sigma=77 \mathrm{MPa}
$$

(b)
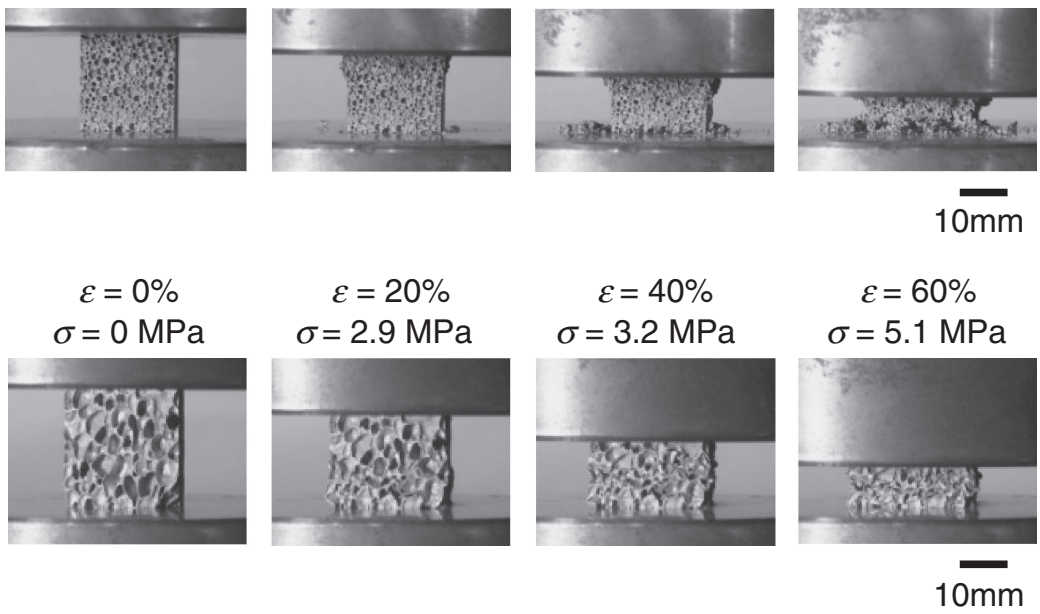

Fig. 9 Sequential deformation images of (a) ADC12 foam II $(p=70.8 \%)$ and (b) ALPORAS $(p=88.9 \%)$.

(a)

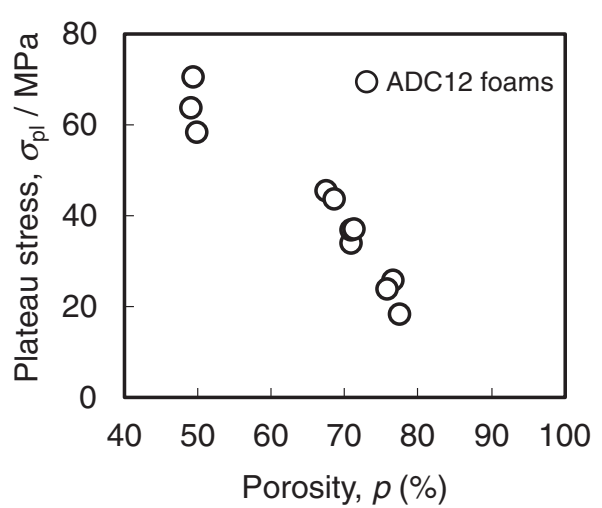

(b)

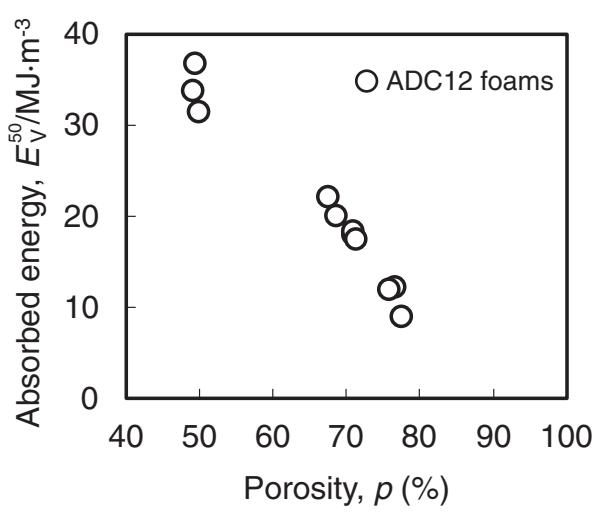

Fig. 10 Relationships between porosity of the foams and plateau stress $\sigma_{\mathrm{pl}}$ and energy absorption per unit volume $E_{\mathrm{V}}{ }^{50}$.

than that of ALPORAS. Also, the highest $E_{\mathrm{V}}$ was observed for the low-porosity ADC12 foam at a lower compression stress but for the high-porosity $\mathrm{ADC} 12$ foam at a higher compression stress. This tendency is considered to be due to the following reason. For the low-porosity ADC12 foam, the low $E_{\mathrm{V}}$ continued in the elastic region up to a high compression stress owing to the high plateau stress. In the plateau region, $E_{\mathrm{V}}$ for the low-porosity $\mathrm{ADC} 12$ foam increased more rapidly with increasing compression strain owing to its higher plateau stress to become larger than that for the high-porosity (a)

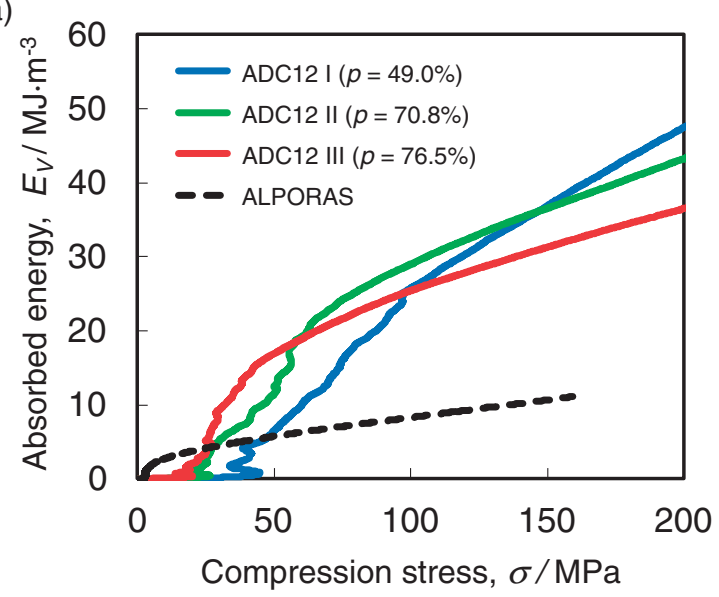

(b)

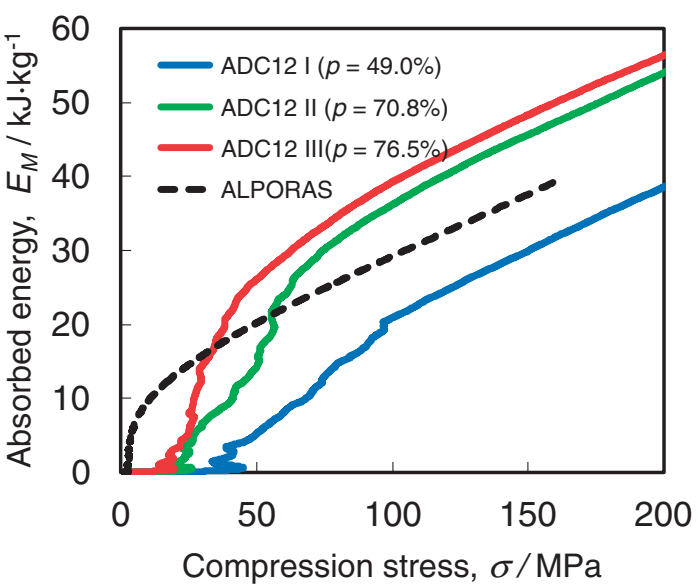

Fig. 11 Relationship between compression stress and energy absorption. (a) Results for energy absorption per unit volume. (b) Results for energy absorption per unit mass.

ADC12 foam. Figure 11(b) shows the relationship between the compression stress $\sigma$ and energy absorption per unit mass $E_{\mathrm{M}}$ (the area under the stress-strain curve up to a specific stress divided by the mass of the foam) of the ADC12 foams with different porosities and ALPORAS. ALPORAS had a 
higher $E_{\mathrm{M}}$ in the first stage of compression up to $\sigma \approx 25 \mathrm{MPa}$, similarly to the behavior of $E_{\mathrm{V}}$ in Fig. 11(a). After the compression stress exceeded $25 \mathrm{MPa}, E_{\mathrm{M}}$ for ADC12 foam III $(p=76.5 \%)$ became higher than that for ALPORAS. This is due to the low density and high plateau stress of ADC12 foam III compared with those of ALPORAS. The effect of the porosity on $E_{\mathrm{M}}$ for the ADC12 foams was different from its effect on $E_{\mathrm{V}}$. Namely, $E_{\mathrm{M}}$ was higher for a higher-porosity ADC12 foam regardless of the compression stress. This is due to the lower density of the higher-porosity ADC12 foam, and therefore it is considered that $\mathrm{ADC} 12$ foam with low density can contribute to realizing lightweight components with high energy absorption.

\section{Conclusions}

In this study, compression tests were conducted on blowing-agent-free aluminum foam fabricated from aluminum alloy die castings. The experimental results led to the following conclusions.

(1) ADC12 foams with porosity from approximately 50$77 \%$ can be successfully fabricated using aluminum alloy die castings, which contain a large number of gas pores, without the use of a blowing agent.

(2) The pore size of the ADC12 foams was almost the same regardless of the amount of gases contained in the die castings. Namely, there were little effect of the porosity of the fabricated foams on the pore size of the ADC12 foams. Also, the pores of the ADC12 foams were smaller than those of ALPORAS.

(3) The ADC12 foams exhibited brittle fracture owing to the Al-Si eutectic microstructure of the cell walls, in contrast to ALPORAS which exhibited ductile fracture.

(4) The plateau stress and energy absorption decreased with increasing porosity, and they indicated the strong relationship.

(5) ALPORAS exhibited higher energy absorption at a low compression stress but the ADC12 foams exhibited higher energy absorption at a high compression stress. Also, the ADC12 foams with higher porosity exhibited higher energy absorption per unit mass, regardless of the compression stress. In contrast, the foam with the highest energy absorption per unit volume changed from the high-porosity $\mathrm{ADC} 12$ foam to the lowporosity $\mathrm{ADC} 12$ foam with increasing compression stress.

\section{Acknowledgments}

The authors thank former Assistant Professor T. Yokota, Shibaura Institute of Technology, and Professor K. Saito, Gunma University, for their helpful advice on conducting the experiments, and former Professor H. Kumehara, Gunma University, for fruitful discussions throughout this study. They are also grateful to Shinko Wire Company, Ltd. for providing the ALPORAS samples. This work was partly financially supported by the Industrial Technology Research Grant Program in 2009 from the New Energy and Industrial Technology Development Organization (NEDO) of Japan and by Grant-in-Aid for Scientific Research (C) (22560705).

\section{REFERENCES}

1) J. Banhart: Prog. Mater. Sci. 46 (2001) 559-632.

2) H. D. Kunze, J. Baumeister, J. Banhart and M. Weber: Int. J. Powder Metall. 25 (1993) 182-185.

3) F. Baumgartner, I. Duarte and J. Banhart: Adv. Eng. Mater. 2 (2000) $168-174$.

4) M. Kobashi, M. Noguchi and N. Kanetake: Mater. Trans. 52 (2011) 934-938.

5) R. Suzuki and K. Kitazono: J. Jpn. Inst. Metals 74 (2010) 314-320.

6) K. Kitazono, E. Sato and K. Kuribayashi: Scr. Mater. 50 (2004) 495498.

7) K. Kitazono, S. Nishizawa, E. Sato and T. Motegi: Mater. Trans. 45 (2004) 2389-2394.

8) S. Tsuda, M. Kobashi and N. Kanetake: Mater. Trans. 47 (2006) 21252130.

9) N. Kanetake, M. Kobashi and S. Tsuda: Adv. Eng. Mater. 10 (2008) $840-844$.

10) Y. Hangai, T. Utsunomiya and M. Hasegawa: J. Mater. Process. Technol. 210 (2010) 288-292.

11) Y. Hangai, K. Takahashi, T. Utsunomiya, S. Kitahara, O. Kuwazuru and N. Yoshikawa: Mater. Sci. Eng. A 534 (2012) 716-719.

12) Y. Hangai and T. Utsunomiya: Metall. Mater. Trans. A 40 (2009) 1284 1287.

13) Y. Hangai, H. Kato, T. Utsunomiya and S. Kitahara: Metall. Mater. Trans. A 41 (2010) 1883-1886.

14) Y. Hangai, H. Kato, T. Utsunomiya and S. Kitahara: J. Jpn. Inst. Metals 74 (2010) 697-699.

15) D. F. Allsop and D. Kennedy: Pressure Diecasting, Part 2, The Technology of the Casting and the Die, (Pergamon Press, Ltd., New York, 1983) pp. 6-7.

16) W. Walkington: Gas Porosity: A Guide to Correcting the Problems, (North American Die Casting Association, Illinois, 2006).

17) T. Utsunomiya, K. Takahashi, Y. Hangai and S. Kitahara: Mater. Trans. 52 (2011) 1263-1268

18) Y. Hangai, K. Takahashi, H. Kato, T. Utsunomiya, S. Kitahara, O. Kuwazuru and N. Yoshikawa: J. Jpn. Inst. Metals 75 (2011) 465-467.

19) Y. Chino, H. Nakanishi, M. Kobata, H. Iwasaki and M. Mabuchi: Scr. Mater. 47 (2002) 769-773.

20) Y. Chino, M. Mabuchi, H. Nakanishi, H. Iwasaki, A. Yamamoto and H. Tsubakino: Mater. Sci. Eng. A 382 (2004) 35-40.

21) F. Garcia-Moreno and J. Banhart: Colloid Surf. A Physicochem. Eng. Asp. 309 (2007) 264-269.

22) T. Miyoshi, M. Itoh, S. Akiyama and A. Kitahara: Adv. Eng. Mater. 2 (2000) 179-183.

23) S. Nishi, K. Makii, Y. Aruga, T. Hamada, J. Naito and T. Miyoshi: KOBE STEEL ENGINEERING REPORTS 54 (2004) 89-94.

24) R. S. Mishra and Z. Y. Ma: Mater. Sci. Eng. R 50 (2005) 1-78.

25) Z. Y. Ma: Metall. Mater. Trans. A 39 (2008) 642-658.

26) Y. S. Sato, S. H. C. Park, A. Matsunaga, A. Honda and H. Kokawa: J. Mater. Sci. 40 (2005) 637-642.

27) K. Nakata, Y. G. Kim, H. Fujii, T. Tsumura and T. Komazaki: Mater. Sci. Eng. A 437 (2006) 274-280.

28) Y. Hangai, Y. Ozeki, S. Kawano, T. Utsunomiya, O. Kuwazuru, M. Hasegawa, S. Koyama and N. Yoshikawa: Mater. Trans. 51 (2010) 548-552.

29) Y. Hangai, S. Maruhashi, S. Kitahara, O. Kuwazuru and N. Yoshikawa: Metall. Mater. Trans. A 40 (2009) 2789-2793.

30) J. Campbell: The new metallrugy of cast metals, Castings, second edition, (Elsevier Ltd., Oxford, 2003).

31) T. Utsunomiya, K. Takahashi, Y. Hangai, S. Kawano, O. Kuwazuru and N. Yoshikawa: J. JILM 60 (2010) 590-595.

32) A. E. Markaki and T. W. Clyne: Acta Mater. 49 (2001) 1677-1686.

33) H. Toda, T. Ohgaki, K. Uesugi, M. Kobayashi, N. Kuroda, T. Kobayashi, M. Niinomi, T. Akahori, K. Makii and Y. Aruga: Metall. Mater. Trans. A 37 (2006) 1211-1219.

34) T. Takagi, Y. Aruga, K. Makii, H. Kanahashi, T. Hamada and T. Miyoshi: KOBE STEEL ENGINEERING REPORTS 58 (2008) 9396.

35) JIS-H-7902: Method for Compressive Test of Porous Metals, (Japanese Standards Association, 2008). 